\title{
Contratempos de infância e morte
}

\section{The setups and backbeats of childhood and death}

Rosana Kohl Bines ${ }^{\star}$

\begin{abstract}
RESUMO $^{1}$
Este ensaio investiga conexões temporais entre as ações de traduzir e esconder, a partir das considerações de Maria Filomena Molder sobre dois textos de Walter Benjamin: "A tarefa do tradutor" e "Criança Escondida". Discute-se a temporalidade contrapontística do jogo mimético, que envolve tradutor e criança escondida. Assim como a criança atrás da porta busca adotar as propriedades do esconderijo, permanecendo ereta como um sólido inanimado para não ser descoberta, o tradutor se alojaria no texto a traduzir, incorporando as propriedades da língua estrangeira na língua própria. Este intercâmbio produziria uma dinâmica temporal intermitente, em que as formas são e deixam de ser, num vai-e-vem entre a afirmação e a negação da vida. Explora-se esta hipótese na leitura de Song for Night (2007) do escritor nigeriano Chris Abani. A novela confecciona uma voz infantil liminar, oscilando entre vida e morte, para contar experiências-limite de vulnerabilidade à violência. Narrada por um menino-soldado escondido na floresta, que tem suas cordas vocais arrancadas na guerra, a obra é o monólogo interior de um narrador emudecido que se comunica com o exterior por língua de sinais. O livro é escrito em inglês, mas a história simula desenrolar-se num dialeto africano inacessível. A tradução se torna assim imperativa, atuando como princípio construtivo da obra, operador de leitura e dispositivo temporal. Além de marcar o ritmo da experiência oscilante do narrador entre ser e não ser mais, produz demora e dificulta a entrada do leitor na obra, estimulando simultaneamente uma atenção crítica aos seus procedimentos e efeitos.
\end{abstract}

Palavras-chave: tradução; infância; morte.

1 O presente trabalho foi realizado com apoio do CNPq, Conselho Nacional de Desenvolvimento Científico e Tecnológico - Brasil. Foi originalmente escrito para o Simpósio "Tradução, contemporaneidade, extemporaneidade" no âmbito do XV Encontro Nacional da Abralic, realizado na UERJ de 19 a 23 de setembro na UERJ. Agradeço aos organizadores do Simpósio, Mauricio Mendonça Cardozo, Helena Martins e Marcelo Jacques de Moraes, pelo impulso motivador que gerou as reflexões aqui apresentadas. Agradeço ainda aos demais colegas que integraram o simpósio pelos comentários e contribuições, que certamente impactaram na versão final deste texto.

* $\mathrm{PUC}-\mathrm{Rio} / \mathrm{CNPq}$ 
Bines, R. K. Contratempos de infância e morte
Revista Letras,

Curitiba, UFPr, n. 95 24-34, jan./jun. 2017. ISSN 2236-0999 (versão eletrônica)

\begin{abstract}
The present essay investigates temporal connections between the acts of translating and hiding, based on Maria Filomena Molder's notes on two texts by Walter Benjamin - "The task of the translator" and "Hidden Child". It further discusses the contrapuntal temporality of the mimetic game, which engages both translator and child. Just as the child behind the door seeks to adopt the properties of the hiding place, by becoming herself an inanimate solid, to avoid being found, so the translator hides himself in the text he will translate, by incorporating the properties of the foreign language into his own. This interchange generates intermittent temporal dynamics that affirms and negates life and time, as the forms alternate between being and ceasing to be. This hypothesis is further pursued in Song for Night (2007), by Nigerian author Chris Abani. The novella creates a child's liminal voice, torn between life and death, in order to convey experiences of extreme vulnerability to violence. Told by a child-soldier who is hiding in the forest and whose vocal cords have been cut in the war, the novella is structured as an inner monologue by a silenced narrator who communicates with the outside world in sign language. The book is written in English but the story seems to unfold in an African dialect that the reader cannot access. Translation thus becomes essential to the novel, working as a structural principle, as a reading procedure, and as a temporal device. Besides marking the rhythmic beat of the narrator's oscillating experience between being and non-being, translation generates delay and hardens the reader's entrance into the work, while fostering a critical attention to its procedures and effects.
\end{abstract}

Keywords: translation; childhood; death. 

arto de uma pequena pista de leitura, colhida de uma entrevista da filósofa portuguesa Maria Filomena Molder, tradutora e comentadora assídua e perspicaz da obra de Walter Benjamin. Nessa entrevista, Molder propõe uma aproximação inusitada entre dois textos a princípio muito distantes do pensador alemão: "A Tarefa do Tradutor," intricado ensaio de 1923, e "Criança Escondida”, curto fragmento de Rua de Mão Única de 1928, cujo início é transcrito abaixo, na tradução de João Barrento:

Já conhece todos os esconderijos da casa, e volta a eles como a uma morada onde sabemos que iremos encontrar tudo no seu lugar. O coração palpita, prende a respiração. Aqui, está encerrada no mundo da matéria. Este torna-se-lhe extremamente nítido, aproxima-se sem uma palavra. Como um enforcado, que só então toma plena consciência do que são a corda e a madeira. A criança atrás das cortinas torna-se ela própria algo de esvoaçante e branco, um fantasma

(BENJAMIN, 2013, p.36)

A propósito desta passagem, Molder comenta: 
Bines, R. K. Contratempos de infância e morte
É interessante pensar na afinidade entre o jogo das escondidas, tal como aqui é exposto pelo autor, e a noção de tradução que defende noutras partes, muito nomeadamente em "A Tarefa do Tradutor". Em ambos os casos, é uma espécie de abrigo que está em causa. De abrigo provisório, porém: de esconderijo, que tem que ser franqueado (no qual se entra e do qual se sai). A criança está escondida atrás da porta como o tradutor, segundo Benjamin, deve ser capaz de se alojar no texto a traduzir, nos interstícios ou intervalos desse texto, e descobrir, experimentando, por mimese, por imitação, não a sua forma externa mas as leis internas que o regem.

(MOLDER, 2014, s/p)

A sugestão de Molder convida a pensar o jogo mimético como prática comum entre o tradutor e a criança escondida. Se para a criança esconder-se supõe adotar a forma e as propriedades do esconderijo, para que permaneça ali camuflada e invisível aos olhos do buscador, para o tradutor trata-se também de entrar num espaço que não é o seu, numa língua que não é a sua, e deixar-se arrastar pelo som, pelo ritmo e pela textura sensível da trama verbal, pois só mergulhando no objeto e seguindo as suas exigências, pode-se verdadeiramente chegar a tocá-lo, como escreve Benjamin na Origem do Drama Trágico Alemão. De fato, em toda obra do pensador, o conhecimento das coisas, do mundo material, das línguas a traduzir surge, no mais das vezes, como um rompante de saída para fora, em direção ao alheio, na busca de uma forma genuína de contato com os materiais de que nos acercamos. Paradoxalmente, esse gesto de evasão para a exterioridade envolve também uma dimensão receptiva. Ato de rendição do próprio corpo, espécie de assujeitamento da própria forma diante da forma estrangeira, como a criança que atrás da porta remolda a si mesma como um sólido inanimado, ereta, imóvel, respiração suspensa. A criança submete-se à fisionomia da porta, deixa-se comandar por ela, experimenta-a corporeamente, numa coreografia visível também nas velhas cartilhas infantis que tanto fascinaram Benjamin, aquelas em que as letras assumem as formas dos bichos e dos objetos cotidianos que nomeiam.

Só quem percorre a estrada a pé (e não em sobrevoo de aeroplano) sente o seu poder e o modo como ela, a cada curva, faz saltar do terreno plano objetos distantes, mirantes, clareiras, perspectivas, diz outra passagem bastante conhecida de Rua de Mão Única. Tal capacidade de gerar novas formas a partir da imersão nos espaços atravessados - sejam estes os cantos entre as mobílias da casa berlinense por onde se mete a criança, sejam as malhas do texto por onde se enfronha o tradutor, encampa um gesto de ampliação das fronteiras do próprio e do alheio. Nesses intercâmbios alargados e táteis com o exterior, o que era limite, barreira, abre-se como limiar, canal de passagem que libera entre as formas ou as línguas em contato uma potencialidade plástica comum a
Revista Letras,

Curitiba, UFPr, n. 95 24-34, jan./jun. 2017. ISSN 2236-0999 (versão eletrônica) 
todas elas, uma força de ativação de correspondências, que acende também um aviso de incêndio, sinal de perigo iminente: confusão mimética. Para a criança escondida, ronda a ameaça de ficar presa "para o resto da vida dentro da pesada porta" ou enredada "para sempre, como fantasma, nas cortinas" (BENJAMIN, 2013, p. 37). Para o tradutor, o perigo de perder a sua língua perante as demandas do idioma estrangeiro, cedendo até o ponto em que a própria língua se torna irreconhecível, como nos balbucios de Hölderlin que Paul Celan homenageou poeticamente: Pallaksch. Pallaksch. ${ }^{2}$

Molder reconhece que o ensaio "A tarefa do Tradutor" de Walter Benjamin não chega a estabelecer uma relação causal direta entre a imersão de Hölderlin nas últimas traduções que fez de O rei Édipo e Antígona de Sófocles e a loucura que o tomou em certo momento nos 40 anos que permaneceu isolado na Torre de Tübingen. Contudo, a filósofa pressente nas reflexões de Benjamin uma sugestão forte de que, naquelas traduções, a relação de fidelidade entre o alemão e o grego se dá de forma tão acentuada que era impossível escrever em língua articulada depois disso. Cito as palavras de Benjamin, ao final do ensaio "A tarefa do tradutor":

Nas traduções de Hölderlin, a harmonia das línguas é tão profunda que o sentido só é tocado pela língua como uma harpa eólica pelo vento [...] Precisamente por isso habita nelas, antes de mais nada, o tremendo e originário perigo de qualquer tradução: que os portões de uma língua tão alargada e bem dominada acabem por se fechar, encerrando o tradutor no seu silêncio ${ }^{3}$

(BENJAMIN, 2008, p. 81).

Hölderlin encarna a imagem extrema e definitiva de alguém que teria passado de vez para outro lado do espelho, abandonando o trânsito lúdico e criador que faz do traduzir e do esconder práticas da intermitência: era uma vez a língua alemã, agora já não mais. Era uma vez o grego, agora já não mais. Era uma vez um menino, agora já não mais. Agora ele era cortina, agora já não mais.

2 A palavra duplicada Pallaksch, Pallaksch é atribuida ao poeta Hölderlin, que viveu encerrado na torre de Tübingen por 40 anos e teria inventado este vocábulo indeterminado, que pode significar tanto sim quanto não. O poema de Paul Celan que homenageia Hölderlin chama-se "Tübingen, Janner" (Tubingen, Janeiro), publicado no livro Die Niemandsrose (A rosa de ninguém): Olhos con-/vertidos à cegueira./A sua - "são/um enigma as puras/"origens" - , a sua/memória de/torres de Hölderlin flutuando no esvoaçar/de gaivotas./ Marceneiros afogados visitando/estas/palavras a afundarem-se:/ Se viesse,/se viesse um homem,/se viesse um homem ao mundo, hoje, com/a barba de luz dos/patriarcas: só poderia,/se falasse deste/tempo, só/poderia/ balbuciar balbuciar/sempre, sempre,/só só./(“Pallaksch. Pallaksch.”). CELAN, P. "A rosa de ninguém.” Sete rosas mais tarde. Trad. João Barrento e Y.K. Centeno. Ed. Bilingue. 3 ed. Lisboa: Cotovia, 199, p.105.

3 Tradução de Susana Kampff Lages, publicada num volume organizado por Lucia Casttello Branco (referido na bibliografia), em que estão incluídas outras três traduções do ensaio benjaminiano "A tarefa do tradutor": as de Fernando Camacho, Karlheinz Barck e João Barrento. 
Bines, R. K. Contratempos de infância e morte

Agora ele era porta, agora já não mais ${ }^{4}$. O ir e vir incessante entre a criança e os objetos ou entre o tradutor e as línguas produz uma dinâmica temporal de feição contrapontística, em que as coisas são e deixam de ser uma e outra vez, num vai-e-vem entre a afirmação e a negação da vida, sem que se fixe uma das imagens apenas.

Do que foi exposto até aqui, gostaria de reter sobretudo essa energia piscante que ativa os gestos do tradutor e da criança escondida. E a sensação de perigo que perpassa ambas as atividades, movidas por um princípio de abertura e provisória rendição às formas estrangeiras com que se põem em contato. Entro então no segundo tempo dessa reflexão, não sem antes lembrar que os perigos vindos do mundo material, que acossam aquele menino escondido na casa berlinense, agem também como prenúncios de perigos futuros, que expulsarão o menino já adulto de sua cidade natal e o obrigarão a escrever e a traduzir "escondido" em cidades estrangeiras como Ibiza, Nice, Sanremo, Svenborg, Paris e Portbou, seu esconderijo derradeiro. É afinal desde o exílio, no contexto da Segunda Guerra, que Benjamin escreve os espaços limiares da infância alemã, exercitando uma dinâmica temporal que Peter Szondi, citado por Jeanne-Marie Gagnebin, chamou argutamente de futuro anterior ${ }^{5}$ e que quero pensar também na chave rítmica do contratempo.

Deixemos então o menino escondido atrás da porta em Berlim por volta de 1900 para encontrar outro menino escondido em uma floresta africana por volta de 1960. Ensaio aqui uma aproximação inicial e bastante cautelosa ao livro Song for Night (Canção para noite) do escritor nigeriano Chris Abani. É um desses livros que nos confrontam com um pacto inicial intimidante e que exigem uma pele mais grossa para tolerar o que ali vai dito. Pele que estas páginas preliminares ajudam a criar, na produção estratégica de certa demora que adia e prepara a minha entrada no texto que passarei a comentar. Cabe antes uma abreviada apresentação do autor, desconhecido do público brasileiro ${ }^{6}$. Chris Abani é um dos expoentes da nova geração de prosadores africanos em língua inglesa, escritor premiado e reconhecido no universo anglófono, ainda não traduzido no Brasil. Nascido em 1966, Abani tornou-se prisioneiro político na Nigéria nos anos oitenta, entrando e saindo da cadeia desde os seus 16 anos, quando publica seu primeiro romance de cunho alegórico, denunciando o golpe de estado que então era levado a cabo no país por forças militares. Condenado à pena de morte anos depois, devido ao cunho fortemente antigovernamental

Revista Letras,

4 Ecoo aqui Maria Filomena Molder (2014, s/p), quando associa o impulso mimético ao princípio lúdico e experimental do "eu agora era...".

5 Jeanne-Marie Gagnebin alude à expressão "futuro anterior" de Peter Szondi no ensaio "A criança no limiar do labirinto", publicado no livro História e Narração em Walter Benjamin (2004), p.89.

6 Para uma aproximação mais efetiva à vida, à obra e às reflexões do autor sobre literatura africana contemporânea, remeto o leitor à entrevista de Chris Abani a Yogita Goyal. "A Deep Humanness, a Deep Grace: Interview with Chris Abani”. Research in African Literatures. v. 45, n. 3, 2014, p. 227-240.

Curitiba, UFPR, n. 95 24-34, jan./jun. 2017. ISSN 2236-0999 (versão eletrônica) 
de seus escritos, consegue ser libertado, por circunstâncias que não cabem aqui detalhar, e imigra inicialmente para o Reino Unido e depois para os Estados Unidos, onde vive e leciona desde 1999. É do exílio norte-americano, na condição de intelectual expatriado, que escreve e publica em língua inglesa, Song for Night, obra de 2007.

Trata-se de uma curta e estranha novela, narrada por um menino-soldado, que se encontra sozinho, escondido (ele também) no meio da mata, em busca de seu pelotão, do qual foi separado após a explosão de uma mina terrestre que o lança com violência ao chão, deixando-o inconsciente e provavelmente morto. É na condição de morto-vivo que essa voz espectral nos chega para entoar discursivamente uma canção para a noite, espécie de canto fúnebre ou réquiem em que se torna audível um ponto de desarticulação do sujeito, ponto em que seu estatuto como vivente já não está mais assegurado. Ainda há pouco estava vivo, agora talvez já não mais. Como nos comunica o narrador, no terreno minado da guerra, tudo acontece bruscamente. "Everything happens rudely, at once" (p. 45) [Tudo acontece de supetão, de repente ${ }^{7}$. No curtíssimo intervalo de um passo mal dado e ouve-se um click. Esse barulhinho a um tempo sutil e fatal que o narrador escuta segundos antes da mina explodir e que denota que o dispositivo foi armado e talvez já não haja mais volta - "an ominous clicking that sounds like the mechanism of a child's toy" (p.22) [um click assustador que soa como o mecanismo de um brinquedo infantil]. A novela estira esse brevíssimo instante que constitui uma extremidade temporal entre ser e não ser mais. $\mathrm{E}$ ao distender-se a narrativa por mais de 100 páginas, o acontecimento que era súbito, único e irrepetível da morte por explosão ganha uma duração inaudita. Que operações discursivas materializam essa intensificação do instante e sua proliferação numa série de minicontratempos que marcam repetidas vezes ao longo da novela essa batida ameaçadora entre vida e morte; esse cruzar intermitente da linha divisória entre ser e não ser mais?

A hipótese principal que exploro aqui é a de que esse "limbo" temporal e existencial se encarna materialmente num conjunto de operações tradutórias que performam um vai-e-vem incessante entre as várias línguas em ação no texto, gerando uma dinâmica instável no registro discursivo que mimetiza a condição liminar do protagonista-narrador. O empenho da novela é o de maximizar a correspondência entre os eventos relatados e a linguagem que os diz. Jogo mimético que os dispositivos da tradução ajudam a encenar.

A frase de abertura da novela enuncia de forma crua e declarativa: "What you hear is not my voice" (p. 19) [o que você ouve não é a minha voz]. Ficamos sabendo nas linhas seguintes que o narrador não fala há três anos, pois teve suas cordas vocais arrancadas no conflito, ao ser recrutado para fazer parte de um grupo especial de crianças combatentes, cuja função é rastrear e desarmar minas

7 Todas as traduções da obra de Chris Abani são minhas. Agradeço a Paulo Henriques Britto a generosa interlocução. 
Bines, R. K. Contratempos de infância e morte
Revista Letras,

Curitiba, UFPr, n. 95 24-34, jan./jun. 2017. ISSN 2236-0999 (versão eletrônica) terrestres espalhadas por toda a floresta. Para executar essa tarefa de alto risco, precisa ser pequeno, esfomeado e leve, de modo a evitar a explosão automática da mina ao pisá-la. E precisa também ser mudo, para que não saia grito da boca do menino que por acaso pise nalguma mina e se assuste com a iminência de morrer. O grito pode comprometer toda a delicada operação do pelotão que caminha silenciosamente descalço na mata e precisa de máxima concentração para ouvir o barulho do click e, com as pontas dos dedos do pé que ficou suspenso enquanto o outro permanece apegado ao solo, grudado na mina, desativar o dispositivo letal.

O livro se configura assim como o monólogo interior de um narrador emudecido cuja língua de expressão não é o inglês que lemos nas páginas do livro, mas sim o Igbo, como nos conta o personagem, um dialeto tribal e familiar, silenciado pela história colonial, que impôs a língua inglesa às populações autóctones.

Cabe aqui abrir um parênteses para apontar o quanto essa situação do enredo repercute também no lugar fraturado e problemático de enunciação que o próprio Chris Abani ocupa como escritor anglófono radicado nos Estados Unidos, que se dirige prioritariamente a uma audiência estrangeira fora da África, para quem busca "traduzir" certas experiências do seu continente natal numa língua majoritária em que já circulam, de forma reificada, determinados sentidos de africanidade com os quais esse livro tem que se haver. Não à toa, o projeto editorial, que considero lamentável, ${ }^{8}$ traz na capa uma foto apelativa, em tecnicolor, de um menino negro com olhos sofridos, que interpela a audiência desse lugar já inteiramente codificado para o leitorado estrangeiro como uma África da barbárie, da violência, da orfandade, à espera da redenção por um Ocidente humanitário e sensível às atrocidades relatadas. Esta reflexão nos levaria longe demais numa discussão, deveras relevante, sobre a tradução vinculada a uma política de leitura das relações neocoloniais com o continente africano, tópico que mereceria um desdobramento à parte9.

Retornemos à narrativa de Song for Night, estruturada como o monólogo interior de um narrador mudo, que se dirige diretamente ao leitor em inglês, mas lhe adverte: "you are in fact hearing my thoughts in Igbo" (p. 21) [na verdade, você está ouvindo meus pensamentos em Igbo]. Simula-se assim uma comunicação telepática entre narrador-leitor, numa língua a que não temos acesso, uma língua que caberá ao inglês traduzir. A esta demanda que pressiona o idioma inglês na direção de uma língua silenciada, soma-se mais um complicador, pois os

8 Ressalto que há outra edição desta obra de Chris Abani, disponível no mercado, com um projeto editorial mais sóbrio. Song for Night. London/Berkley: Telegram, 2008.

9 Para uma discussão mais alentada sobre os desafios e impasses na representação de meninos-soldado africanos na literatura contemporânea, em interface com a obra de Chris Abani, ver em especial os seguintes ensaios, referidos em detalhe na bibliografia: Maureen Moynagh, "Human Rights, Child-Soldier Narratives, and the Problem of Form"; Minoli Salgado, "Vanishing points/visible fictions: the textual politics of terror"; J.A. Kearney, "The representation of Child Soldiers in Contemporary African Fiction". 
meninos do pelotão, que tiveram suas cordas vocais arrancadas, se comunicam entre si apenas por uma língua de sinais. É portanto uma história que se lê em inglês, mas que no plano do enredo se desenvolve mentalmente em Igbo, na subjetividade da personagem, e se exterioriza como mímica de gestos. É interessantíssimo observar os expedientes narrativos que vão encenar no tecido verbal um gestual mudo de pantomima. Todos os títulos de capítulos da novela enunciam operações tradutórias entre o inglês e a língua de sinais: "Silence is a steady Hand, Palm Flat" [Silêncio é uma mão firme, palma esticada"]; "Death is two fingers sliding across the throat" [Morte são dois dedos trespassando a garganta]; "Listening is a hand cupping an ear like a seashell" [Escutar é uma mão em volta da orelha como uma concha]; "Fish is a hand swimming through the air" [Peixe é uma mão nadando no ar]; "Shelter is hands protecting the head" [Abrigo é mãos protegendo a cabeça].

Nesta coleção de verbetes ou definições de palavras por sua contraparte gestual a língua ganha uma plasticidade surpreendente, como que se avoluma na direção do leitor, ganhando corpo e movimento numa encenação de tensões enunciativas que parecem implodir a superfície plana dos caracteres na página com uma força de expansão projetiva que vejo como afinada à cena da explosão da mina que dá pulso à narrativa e informa a voz do narrador-protagonista em sua condição limítrofe. O que desejo apontar aqui é que a tradução, tomada como conjunto de operações discursivas, colabora de forma decisiva com os processos de formalização de estados de passagem, levando a língua verbal e impressa a um limiar em que ela parece transbordar para uma nova configuração tridimensional e cinética. Essa dinâmica de instabilidade do próprio meio que conduz a narrativa manifesta também a vulnerabilidade da língua ao que ela não é, ao que ela pode vir a ser numa aproximação desmedida e arriscada com seu exterior, abolindo-se o princípio da fronteira e rompendo-se os limites da página para ressurgir como coreografia manual de gestos, do "lado de cá" da experiência empírica e encarnada do leitor.

A contraparte temporal dessa operação tradutória que faz da língua verbal pantomima, encaminhando o som a regiões de silêncio, par e passo com a trajetória do personagem vulnerável, oscilando, entre a voz e a ausência de voz, entre vida e morte, é uma rítmica em contraponto, feita de frases curtíssimas, que impõem uma leitura entrecortada e impede que se assente qualquer sentido de progressão narrativa. A história não avança pra lugar nenhum e mantém-se em intolerável suspensão: "Time is standing still. My watch is fucked" (p. 54) [O tempo está parado. Meu relógio está fodido]. A narrativa é coalhada de passagens como esta em que algo é dito num registro metafórico (a sensação do tempo congelado) e redito, traduzido, na frase seguinte num registro asperamente literal (o tempo não anda porque o relógio está quebrado). Esta sintaxe do contratempo trava o desdobramento especulativo dos episódios, condenando qualquer tentativa de voo digressivo. Toda vez que o enunciado ameaça decolar do chão, pelo 
Bines, R. K. Contratempos de infância e morte

emprego dicção conotativa, há um movimento oposto de rebaixamento do idioma, criando uma caixa de ressonâncias com efeitos de microfonia, em que ouvimos registros discrepantes - o metafórico e o literal - registros que não se harmonizam e evidenciam intervalos acentuados entre eles, impedindo a fruição de um contínuo de sentido. A leitura extensiva do texto entra assim em colapso. Tudo a ponto de explodir. O dispositivo da tradução agrava essa experiência, na medida em que força correspondências entre sentidos discrepantes. Numa outra cena, mulheres famintas parecem compartir, num gesto solidário, da pouca comida que lhes resta. Vista mais de perto, a cena revela que o alimento do grupo é na verdade o crânio de uma criança morta. O leitor é jogado pra lá e pra cá entre essas polaridades revezadas de maneira abrupta e cruel. São contratempos que desejo ler também como obstáculos, adversidades no percurso de leitura. Também aí o jogo tradutório, lido como jogo mimético, trabalha para assimilar, no emaranhado verbal, a fisionomia compósita do menino-soldado, no que ali pode haver de inabordável e resistente. Como ler afinal o menino embolado no soldado, a infância na guerra, o vivo no morto?

Esta dificuldade, de natureza ética, se materializa na novela como um problema de tradução: What you hear is not my voice. Há algo de opaco nessa história. Os expedientes da tradução colaboram na criação desta espessura, dessa demora que freia um acesso desimpedido ao relato, produzindo de forma paradoxal tanto uma conexão visceral com essa matéria intratável, quanto um recuo favorável ao estabelecimento de uma atenção crítica aos procedimentos e efeitos no jogo narrativo. Nessa dinâmica tensionada, em que somos tragados e expulsos da narrativa, uma e outra vez, atravessa-se uma fabulação de força ímpar, que poderá servir de abrigo provisório ao leitor que ali tolerar se alojar pelo tempo de duração da leitura. Terá valido a pena.

Revista Letras, 
ABANI, C. Song for Night. New York: Akashic Books, 2007.

BENJAMIN, W. "A tarefa do tradutor". A tarefa do tradutor: quatro traduções para o português. Lucia Castello Branco (Org.). Belo Horizonte: Fale UFMG, 2008.

. "Criança escondida". Rua de Mão Única: Infância Berlinense.

Trad. João Barrento. Belo Horizonte: Autêntica, 2013. p. 36-37.

CELAN, P. "A rosa de ninguém." Sete rosas mais tarde. Tradução de João

Barrento e Y.K. Centeno. Edição Bilingue. 3 ed. Lisboa: Cotovia, 199, p.105.

GAGNEBIN, J-M. "A criança no limiar do labirinto”. $2^{a}$ edição. São Paulo: Perspectiva, 2004, pp.73-92.

GOYAL, Y. "A Deep Humanness, a Deep Grace: Interview with Chris

Abani." Research in African Literatures. Vol. 45, nº 3 (Fall 2014), pp. 227-240.

KEARNEY, J. A. "The representation of Child Soldiers in Contemporary

African Fiction.” JLS/TLW nº 26 (March 2010), pp.67-94.

MOLDER, M. F. "A propósito de uma tradução”. Semear na neve: estudos sobre Walter Benjamin. Lisboa: Relógio D’Água Editores, 1999. p. 24-39.

. "Aquele que acaba de despertar". Semear na neve: estudos sobre Walter Benjamin. Lisboa: Relógio D’Água Editores, 1999. p. 119-137.

"Seguir as dedadas da infância: conversa com

Maria Filomena Molder”. Entrevista a Emília Pinto de Almeida em 6 de outubro de 2014. Esc:ALA. Revista Electrónica de estudos e práticas interartes, Instituto de Literatura Comparada Margarida Losa, 2014. Disponível em <https://escalanarede.com/2014/10/06/ seguir-as-dedadas-da-infancia-conversa-com-maria-filomena-molder $>$. Acesso em: 23 ago. 2016.

MOYNAGH, M. "Human Rights, Child-Soldier Narratives, and the Problem of Form”. Research in African Literatures, v. 42, n. 4, p. 39-59.

SALGADO, M. "Vanishing points/visible fictions: the textual politics of terror”. Textual Practice n 27, New York/London: Routlege, pp. 207-223.

Submetido em: 30/09/2016

Aceito em: 20/12/2016 